\title{
Attitudes and Intentions of Greek Athletes and Coaches Regarding Doping
}

\author{
Stavroula Psouni, Nikos Zourbanos, Yannis Theodorakis \\ University of Thessaly, Thessaly, Greece \\ Email: nzourba@pe.uth.gr
}

Received 11 August 2015; accepted 25 September 2015; published 28 September 2015

Copyright (C) 2015 by authors and Scientific Research Publishing Inc.

This work is licensed under the Creative Commons Attribution International License (CC BY). http://creativecommons.org/licenses/by/4.0/

(c) (;)

\section{Abstract}

The aim of this study was to examine athletes' and coaches' attitudes and intentions with regard to doping, using the theory of planned behavior (TPB) model. This model [1], explains all the behaviors which are related to self-control, based to the theory that intentions are influenced by attitude, perceived behavioral control and subjective norms. The variable "morality" was added to the original model. One hundred and forty-three athletes (mean age $=20.93 \pm 2.90$ ) who were involved in competitive sports and 50 coaches (mean age $=35.74 \pm 7.80$ ) participated in the study. A questionnaire was administered to assess the demographics (age, gender, sport type, competitive level, years of sport participation and education), attitudes, subjective norms, perceived behavioral control, intentions, morality and doping choices of athletes and coaches with regard to doping. The results showed that attitudes (62\%), perceived behavioral control (3\%), and morality (4\%) were significant predictors of athletes' intentions to engage in doping choices but that coaches' only attitudes were the most important predictor of intentions to engage in doping choices (72\%). The most important predictors of $1^{\text {st }}$ and $2^{\text {nd }}$ doping choices were intentions $(78 \%$ and $68 \%)$ and perceived behavioral control $(1 \%)$ for athletes and intentions $(84 \%$ and $79 \%)$ for coaches.

\section{Keywords}

Athletes, Doping Choices, Doping Attitudes, Morality, Planned Behavior Theory

\section{Introduction}

According to the World Anti-Doping Agency, doping is defined as the violation of various anti-doping rules established by the World Anti-Doping Code [1] [2]. Research has shown that external factors, such as excessive media exposure, economic rewards [3] and the commercialization of sports [4] are linked to doping (use of illegal performance-enhancing substances). Additionally, doping has been related to attitudes and intentions regarding 
use [5]-[9] of other substances, low self-esteem, ego-oriented achievement, striving, narcissism, depression [10], lack of self-esteem [11], eating disorders, body image imbalance, a dispositional risk-taking propensity, stress [12], psychiatric effects [13] [14] and health risks [15]. "Doping choices" refers to the use of substances to enhance performance [16]. Efforts to combat doping in sports are focused mainly on control (laboratory testing) rather than on prevention [17]-[19]. According to Ehrnborg and Rosen [20], athletes have to consider two main risks before using drugs: the risk of negative health effects and the risk of getting caught. Morality is another factor that can inhibit doping among athletes [21] [22].

The theory of planned behavior (TPB) has been used to analyze and explain the factors that can predict specific behaviors. According to literatures [23]-[25], specific psychosocial variables can predict behavior. The TPB suggests that a combination of (a) attitudes toward the behavior, (b) subjective norms, and (c) perceived behavioral control determines an individual's intentions to perform a certain behavior [26]. More analytically, attitudes toward a behavior are defined as the overall positive or negative evaluation of the behavior. Perceived behavioral control refers to the individual's beliefs about the ease or difficulty of performing specific behaviors. Finally, subjective norms are the perceptions of whether significant others will approve or disapprove of the behavior.

Results presented by Lucidi, Grano, Leone, Lombardo, and Pesce [27] showed that attitudes were the main factor in predicting doping intentions, followed by perceived behavioral control. In another study, Lucidi et al. [28] found a positive relationship between doping and attitudes' toward doping in a sample of Italian athletes. Their results revealed that athletes believed that doping would be accepted by significant others. Petróczi and Aidman [29] revealed that athletes who had indulged in doping behavior at some point in their careers had more tolerant attitudes toward doping than those who had not engaged in doping behavior. The above findings provide a basis for an investigation of the links between the TPB and doping use. Numerous studies have examined the psychological factors that contribute to doping in sport from the perspective of the TPB, and some of them have included additional variables, such as moral norms [30] [31].

Petróczi et al. [32] indicated that morality, social pressure from significant others, self-esteem, conscientiousness, and a high perception of risk were inhibitors of doping use. Morality can determine the formulation of attitudes toward anabolic drug use [33]. The review of Morente-Sanchez and Zabala [34] referred that athletes considered that doping was cheating. Kaiser [35] stated that attitudes represent the individual view of morality and that morality can be the basis for the development of attitudes.

Therefore, the objective of the present study was to examine athletes' and coaches' attitudes and intentions regarding doping choices taking into consideration morality as an extra variable. The TPB model predicts an individual's intention to a specific behavior using as key components attitude about behavior, perceived behavioral control and subjective norm. We expanded TPB model by adding one more variable according the model of Theodorakis [26]. In addition, second aim of the study was to examine the demographic differences in the TPB variables.

\section{Method}

\subsection{Participants}

The participants of the study consisted of 143 athletes (mean age $20.93 \pm 2.90$ ys, 75 men, 68 women) from different sports and 50 coaches (mean age $35.74 \pm 7.80$ ys, 31 men 29 women). The athletes were actively competing at club or local level $(n=54)$, national level $(n=47)$, or international level $(n=42)$. The coaches trained athletes at club or local level $(n=15)$, national level $(n=20)$, or international level $(n=15)$. Seventy-five of the athletes were competing in individual sports, and 69 were competing in team sports. Thirty-three coaches trained athletes in individual sports, and 17 trained athletes in team sports. The main criterion for an individual enrollment in the study was the involvement with sports as an athlete or a coach, the systematic participation in trainings and the participation in sport games and competitions. Athletes or coaches who did not participate at least to one official sport event were excluded.

\subsection{Procedure}

The participants completed self-report measures of the TPB after training, at their own pace. They were assured that the questionnaires were anonymous and that their responses would be used exclusively for research purposes. 
Permission to conduct the study was obtained by the institution's research ethics committee. The participants were informed about the objectives of the study via a written explanation on the first page of the questionnaire. They were advised that participation was voluntary and that they are free not to consent or to interrupt their participation whenever they want. In the instructions of the questionnaire the participants are informed that they are free to decide whether to participate or not in the survey. The protocol for the research project has been approved by the internal ethics committee of university of Thessaly.

\subsection{Measures}

The athletes' questionnaire was designed based on the principles of the TPB [36] about doping. It consisted of 26 items in total as follows:

The first part of the athletes' questionnaire consisted of a hypothetical doping scenario. Scenario was given to simulate the environment for an option of a behavioral expression. [37] as follows: "Imagine that you are a high-level athlete and that you have a good chance of winning a gold medal in the Olympic Games. The coach and the doctor of the team say that you will only win with doping use. They assert that there is no chance of detection and no chance that the drugs will affect your health. They also emphasize the substantial economic rewards and the glory that a win will bring." The coaches' questionnaire asked the participants to imagine that they were coaches of elite athletes, who had a good chance of a gold medal in the Olympic Games only if they engaged in doping, with no chance of detection. The scenario also emphasized the major economic rewards and glory.

Doping choices. Doping choices, defined as the final decisions regarding doping in response to the specific statements of the scenario. We consider doping choices as the express in athletes and coaches behavior. It was assessed with two11-point bipolar adjectives scales (use doping-do not use doping). The statement of $1^{\text {st }}$ doping choice was: "If you were an athlete with a chance of an Olympic victory only with doping use, with no chance of detection, what would be your choice?" and the statement of $2^{\text {nd }}$ doping choice was: "If you were an athlete with a chance of winning an Olympic medal only with doping use, with no chance of detection, what would be your choice?" The coaches were given two similar statements. The statement of the $1^{\text {st }}$ doping choice was: "If you trained athletes with a chance of an Olympic victory only if they engaged in doping use, with no chance of detection, what would be your choice?" and the statement of the $2^{\text {nd }}$ doping choice was: "If you trained athletes with a chance of an Olympic medal only if they engaged in doping use, with no chance of detection, what would be your choice?"

Intentions. Intention refers to the motivation in expressing and influencing a behavior in a specific place and time. To assess the intentions of both the athletes and coaches, we used the following item: I would try to engage in doping under those circumstances. The answers were assessed with a 7-point bipolar adjective scale (likely-unlikely, yes-no, true-false). The Cronbach's alpha for this scale was 0.55 for the athletes' questionnaire, and it was 0.56 for the coaches' questionnaire.

Attitudes. Attitude refers to the degree that an individual has positive or negative evaluation of a behavior. To assess attitudes, we used a 7-point bipolar adjective scale for both the athletes and coaches (good-bad, silly-clever, useful-useless, moral-immoral, ugly-nice, unpleasant-pleasant). The statement that preceded the adjectives was: "Under these conditions, for me, doping would be...” The Cronbach's alpha for this scale was 0.81 for the athletes' questionnaire, and it was 0.88 for the coaches' questionnaire.

Subjective norms. Subjective norms refers to the other people's beliefs, about a behavior. The approval or disapproval of a behavior from other people is important and influence the result. To assess subjective norms, we used a 7-point bipolar adjective scale for both the athletes and coaches (should -should not, true-false, accept-reject). The statement that preceded the adjectives was: "Most people important to me would believe that I should use doping under those circumstances.” The Cronbach's alpha for this scale was 0.85 for the athletes' questionnaire, and it was 0.91 for the coaches' questionnaire.

Perceived behavioral control. Perceived behavioral control refers to the perception of an individual to perform a behavior easily or difficulty. To assess perceived behavioral control, we used a 7-point bipolar adjective scale for both the athletes and coaches (easy-difficult, true-false, agree-disagree, controlled-not controlled). The statement that preceded the adjectives was: "For me doping, use under the above conditions are..." The Cronbach's alpha for this scale was 0.92 for the athletes' questionnaire, and it was 0.97 for the coaches' questionnaire. 
Morality. Morality was included as an additional variable in the TPB model of Theodorakis [26]. It refers to right and wrong decisions and actions according the ethics of a subject. To assess morality, the athletes and coaches responded to the following three statements. First was: "I would feel guilty engaging in doping under these conditions" second was: "Doping is against my principles" and third was: "I would feel morally wrong in doping under these conditions". The answers were assessed on a 7-point bipolar adjective scale (right-wrong, likely-unlikely, agree-disagree). The Cronbach's alpha for this scale was 0.65 for the athletes' questionnaire, and it was 0.49 for the coaches' questionnaire.

Demographics. At the bottom of both questionnaires, the participants provided information on their age (athletes: under 2021 - 2526 - 30, or over 31, coaches: under 30, 31 - 40, or over 41), gender, sport type (team or individual), competitive level (local, national, or international), educational level, and years of sport participation (under 5, 5 - 10, or over 11).

\subsection{Data Analysis}

The statistics analysis was performed using SPSS software, version 20. Descriptive analysis, Cronbach's alpha, t-test, one way Anova and hierarchical regression analysis were used for results procedure.

\section{Results}

\subsection{Differences between Demographic Characteristics}

Gender differences. Independent $t$-tests indicated significant differences between male and female athletes in the variables of $1^{\text {st }}$ doping choice: $F_{(1,141)}=5.63, \mathrm{p}<0.01$; attitudes $\mathrm{F}_{(1241)}=11.03, \mathrm{p}<0.001$; intentions $F_{(1241)}=$ 18.42 , p $<0.001$; perceived behavior control $F_{(1241)}=6.43$, $\mathrm{p}<0.01$; and morality $F_{(1,141)}=6.06, \mathrm{p}<0.01$, with the men having higher scores than the women. There were no statistically significant differences between the male and female coaches in these variables. This finding showed that men athletes are more positive to doping than women.

Differences between the athletes and coaches. Statistically significant differences between the athletes and coaches were revealed only in the $1^{\text {st }}$ doping choice: $t_{(1291)}=2.2, \mathrm{p}<0.05$. Differences between the athletes' and coaches' scores for the other variables were non-significant.

Type of sport. There were significant differences in the athletes' attitudes, depending on whether they participated in team or individual sports: $t_{(1241)}=1.11, \mathrm{p}<0.05$. However, there were no significant differences in the coaches' attitudes according to the type of sport. This finding indicated that athletes who participated in team sports have more positive doping attitudes than athletes who participated in individual sports.

Age. There were no statistically significant differences in athletes as like coaches according age variable. Post hoc tests showed no significant effect of the athletes' age groups. In the coaches' age groups, post hoc tests showed significant differences in $1^{\text {st }}$ doping choice between $31-40(4.08 \pm 3.75)$ years and over 41 years $(1.38$ \pm 1.38 ), attitudes between 31 - 40 years $(14.43 \pm 7.37)$ and over 41 years ( $8.49 \pm 5.43)$, perceived behavioral control between under 30 (15.21 \pm 5.89$)$ and over 41 years (11.15 \pm 5.39$)$, and subjective norms between under $30(11.57 \pm 6.88)$ and over 41 years $(7.92 \pm 4.97)$. This finding showed that younger coaches are more positive to doping than older.

Level of sport participation. With regard to the variable of level of sport participation, there were non-significant differences in the athletes' sample. For the variable of the coaches' competitive level, the results revealed significant differences in the $1^{\text {st }}$ doping choice $\left(F_{(3,49)}=2.94, \mathrm{p}<0.05\right) 2^{\text {nd }}$ doping choice $\left(F_{(3,49)}=2.80, \mathrm{p}=0.05\right)$, intentions $\left(F_{(3,49)}=2.90, \mathrm{p}<0.05\right)$, and perceived behavioral control $\left(F_{(3,49)}=3.55, \mathrm{p}<0.05\right)$. In general, post hoc tests revealed higher mean scores in the category of local level.

Years of sports participation. There were no statistically significant differences in regard to the number of years of sports participation in athletes sample as like in coaches' sample. In the variable of years in sports participation, post hoc tests of the athletes revealed statistically significant differences between the athletes who had participated in sports for less than 5 years $(15.14 \pm 5.27)$ and those who had participated for more than 11 years (18.52 \pm 5.48$)$ only in the variable of perceived behavioral control.

Education. There was no statistically significant difference in regard to the variable of education for both athletes and coaches samples. 


\subsection{TPB: Descriptive Statistics and Correlations}

The TPB, descriptive statistics, and Pearson correlations are presented in Table 1 and Table 2 for the athletes and coaches, respectively. With regard to $1^{\text {st }}$ and $2^{\text {nd }}$ doping choices, $61.5 \%$ and $62.2 \%$ of the athletes were negative, $5.6 \%$ and $3.5 \%$ were undecided, and $32.9 \%$ and $34.3 \%$ were positive, respectively, about doping use. With regard to $1^{\text {st }}$ and $2^{\text {nd }}$ doping choices, $61.5 \%$ and $62.2 \%$ of the coaches were negative, $6 \%$ and $8 \%$ were undecided, and $32.9 \%$ and $34.3 \%$ were positive, respectively, about doping use. In general, the results showed that attitudes, subjective norms, perceived behavioral control, doping intentions, and morality were positively related to the athletes' selection of $1^{\text {st }}$ and $2^{\text {nd }}$ doping choice.

The athletes' scales showed high internal consistency with the Cronbach's alpha, ranging from 0.81 to 0.92 , except morality and perceived behavioral control, which were 0.65 and 0.55 respectively. With regard to the coaches, the results revealed positive relationships between attitudes, subjective norms, perceived behavioral control, intentions, morality, and the $1^{\text {st }}$ and $2^{\text {nd }}$ doping choices. In addition, the coaches' scales showed acceptable internal consistency with Cronbach's alpha, ranging from 0.88 to 0.97 , except for morality and perceived behavioral control, which were 0.49 and 0.56 respectively.

Table 1. Athletes' descriptive statistics, correlations, and Cronbach's alpha coefficients.

\begin{tabular}{|c|c|c|c|c|c|c|c|}
\hline Variables & 1 & 2 & 3 & 4 & 5 & 6 & 7 \\
\hline \multicolumn{8}{|l|}{ 1. Morality } \\
\hline 2. Intentions & $0.64^{* *}$ & & & & & & \\
\hline 3. Subjective norms & $0.27^{* *}$ & $0.37^{* *}$ & & & & & \\
\hline 4. Perceived control & $0.43^{* *}$ & $0.57^{* *}$ & $0.36^{* *}$ & & & & \\
\hline 5. Attitudes & $0.61^{* *}$ & $0.79^{* *}$ & $0.49^{* *}$ & $0.52^{* *}$ & & & \\
\hline 6. $1^{\text {st }}$ doping choice & $0.59^{* *}$ & $0.88^{* *}$ & $0.37^{* *}$ & $0.59^{* *}$ & $0.74^{* *}$ & & \\
\hline 7. $2^{\text {nd }}$ doping choice & $0.58^{* *}$ & $0.82^{* *}$ & $0.40^{* *}$ & $0.53^{* *}$ & $0.70^{* *}$ & $0.90^{* *}$ & \\
\hline Mean & 7.00 & 8.90 & 12.80 & 17.70 & 15.80 & 4.50 & 4.70 \\
\hline$(S D)$ & $(4.20)$ & $(6.00)$ & $(6.80)$ & $(5.40)$ & $(8.20)$ & $(4.50)$ & $(3.50)$ \\
\hline Alpha & 0.65 & 0.92 & 0.85 & 0.55 & 0.81 & - & - \\
\hline
\end{tabular}

${ }^{* *} \mathrm{p}<0.001$.

Table 2. Coaches’ descriptive statistics, correlations, and Cronbach's alpha coefficients.

\begin{tabular}{|c|c|c|c|c|c|c|c|}
\hline Variables & 1 & 2 & 3 & 4 & 5 & 6 & 7 \\
\hline \multicolumn{8}{|l|}{ 1. Morality } \\
\hline 2. Intentions & $0.72^{* *}$ & & & & & & \\
\hline 3. Subjective norms & $0.43^{* *}$ & $0.64^{* *}$ & & & & & \\
\hline 4. Perceived Control & $0.42^{* *}$ & $0.64^{* *}$ & $0.47^{* *}$ & & & & \\
\hline 5. Attitudes & $0.72^{* *}$ & $0.87^{* *}$ & $0.61^{* *}$ & $0.66^{* *}$ & & & \\
\hline 6. $1^{\text {st }}$ doping choice & $0.70^{* *}$ & $0.92^{* *}$ & $0.55^{* *}$ & $0.64^{* *}$ & $0.81^{* *}$ & & \\
\hline 7. $2^{\text {nd }}$ doping choice & $0.69^{* *}$ & $0.89^{* *}$ & $0.61^{* *}$ & $0.64^{* *}$ & $0.85^{* *}$ & $0.81^{* *}$ & \\
\hline Mean & 6.7 & 7.6 & 13.7 & 17.7 & 12.7 & 4.55 & 4.7 \\
\hline$(S D)$ & $(4.0)$ & (5.8) & $(5.3)$ & $(5.4)$ & $(7.6)$ & $(4.5)$ & (3.5) \\
\hline Alpha & 0.49 & 0.97 & 0.91 & 0.56 & 0.88 & - & - \\
\hline
\end{tabular}




\subsection{Prediction of Intentions}

We performed hierarchical regression analyses to predict intentions. All the regression models satisfied the homoscedasticity and normality of residuals assumptions. The order of the variables was determined by an expanded version of TBP model of Theodorakis [26], as follows: In the analyses, attitudes were entered in step 1, subjective norms in step 2, perceived behavioral control in step 3, and morality in step 4 (Table 3). Step 1 of the hierarchical regression revealed that attitudes significantly predicted intentions, accounting for $62 \%$ of the variance $\left(F_{(1241)}=237.15, \mathrm{p}<0.001\right)$. In step 2 , attitudes and subjective norms failed to account for a significant proportion of the variance in intentions. When perceived behavioral control was entered in step 3, this significantly added to the model, accounting for $3 \%$ of the variance in intentions $\left(F_{(1239)}=15.79, \mathrm{p}<0.001\right)$. Finally, in step 4, morality accounted for a further significant proportion $(4 \%)$ of the variance in intentions $\left(F_{(1238)}=\right.$ $11.24, \mathrm{p}<0.001)$. This finding showed that all the variables appeared a significant proportion of the variance of athletes' intentions. With regard to the prediction of coaches' intentions (Table 4), in step 1, attitudes significantly predicted $76 \%$ of the variance $\left(F_{(1,48)}=154.2, \mathrm{p}<0.001\right)$. Although, in the first step attitudes appeared a high and significant prediction, in the second, third, and fourth steps, subjective norms, perceived behavioral control, and morality failed to account for a significant proportion of the variance in coaches' intentions.

Table 3. Prediction of athletes' intentions and doping choices: hierarchical regression analysis.

\begin{tabular}{|c|c|c|c|c|c|c|c|c|}
\hline & $B$ & $S E b$ & $\mathrm{R}^{2}$ & F change & $\beta_{1}$ & $\beta_{2}$ & $\beta_{3}$ & $\beta_{4}$ \\
\hline \multicolumn{9}{|l|}{ Intentions } \\
\hline 1. Attitudes & 0.58 & 0.03 & $0.62^{* *}$ & $237.15^{* *}$ & $0.79^{* *}$ & $0.80^{* *}$ & $0.69^{* *}$ & $0.58^{* *}$ \\
\hline 2. Subjective norms & -0.01 & 0.05 & 0.62 & 0.09 & & -0.01 & -0.05 & -0.03 \\
\hline 3. Perceived behavioral control & 0.25 & 0.06 & $0.65^{* *}$ & $15.79^{* *}$ & & & $0.23^{* *}$ & $0.19^{*}$ \\
\hline 4. Morality & 0.29 & 0.08 & $0.69^{*}$ & $11.24^{* *}$ & & & & $0.20^{*}$ \\
\hline \multicolumn{9}{|l|}{$1^{\text {st }}$ doping choice } \\
\hline 1. Intentions & 0.55 & 0.02 & $0.78^{* *}$ & $502.05^{* *}$ & $0.88^{* *}$ & $0.80^{* *}$ & $0.78^{* *}$ & \\
\hline 2. Perceived control & 0.09 & 0.03 & $0.79^{*}$ & $7.85^{*}$ & & $0.13^{*}$ & $0.12^{*}$ & \\
\hline 3. Morality & 0.032 & 0.04 & 0.79 & 51 & & & 0.03 & \\
\hline \multicolumn{9}{|l|}{$2^{\text {nd }}$ doping choice } \\
\hline 1. Intentions & 0.48 & 0.02 & $0.68^{* *}$ & $308.33^{* *}$ & $0.82^{* *}$ & $0.78^{* *}$ & $0.73^{* *}$ & \\
\hline 2. Perceived control & 0.05 & 0.03 & 0.69 & 2.01 & & 0.08 & 0.07 & \\
\hline 3. Morality & 0.06 & 0.05 & 0.69 & 1.62 & & & 0.07 & \\
\hline
\end{tabular}
${ }_{\mathrm{p}}^{*}<0.01,{ }^{* *} \mathrm{p}<0.001$

Table 4. Prediction of coaches' intentions and doping choices: hierarchical regression analysis.

\begin{tabular}{|c|c|c|c|c|c|c|c|c|}
\hline & $B$ & $S E b$ & $\mathrm{R}^{2}$ & F change & $\beta_{1}$ & $\beta_{2}$ & $\beta_{3}$ & $\beta_{4}$ \\
\hline \multicolumn{9}{|l|}{ Intentions } \\
\hline 1. Attitudes & 0.67 & 0.05 & $0.76^{* *}$ & $154.20^{* *}$ & $0.87^{* *}$ & $0.77^{* *}$ & $0.71^{* *}$ & $0.54^{* *}$ \\
\hline 2. Subjective norms & 0.13 & 0.06 & 0.78 & 3.83 & & 0.16 & 0.15 & 0.15 \\
\hline 3. Perceived behavioral control & 0.10 & 0.10 & 0.78 & 1.08 & & & 0.09 & 0.12 \\
\hline 4. Morality & 0.32 & 0.14 & 0.80 & 2.64 & & & & 0.22 \\
\hline \multicolumn{9}{|l|}{$1^{\text {st }}$ doping choice } \\
\hline 1. Intentions & 0.52 & 0.03 & $0.84^{* *}$ & $269.58^{* *}$ & $0.92^{* *}$ & $0.87^{* *}$ & $0.82^{* *}$ & \\
\hline 2. Perceived control & 0.04 & 0.04 & 0.85 & 0.99 & & 0.07 & 0.07 & \\
\hline 3. Morality & 0.02 & 0.03 & 0.85 & 0.59 & & & 0.03 & \\
\hline \multicolumn{9}{|l|}{$2^{\text {nd }}$ doping choice } \\
\hline 1. Intentions & 0.49 & 0.03 & $0.79^{* *}$ & $183.99^{* *}$ & $0.89^{* *}$ & $0.81^{* *}$ & $0.72^{* *}$ & \\
\hline 2. Perceived control & 0.49 & 0.04 & 0.80 & 1.78 & & 0.11 & 0.13 & \\
\hline 3. Morality & 0.02 & 0.03 & 0.80 & 0.86 & & & -0.03 & \\
\hline
\end{tabular}




\subsection{Prediction of Doping Choices}

Hierarchical regression analysis was performed to predict the athletes' $1^{\text {st }}$ and $2^{\text {nd }}$ doping choices (Table 3$)$. In step 1 , intentions significantly predicted the $1^{\text {st }}$ and $2^{\text {nd }}$ doping choices, accounting for $78 \%\left(F_{(1241)}=502.0, \mathrm{p}<\right.$ $0.001)$ and $68 \%$ of the variance $\left(F_{(1241)}=308.3, \mathrm{p}<0.001\right)$, respectively. In step 2, perceived behavioral control explained only $1 \%$ of the variance in $1^{\text {st }}$ doping choice $\left(F_{(1241)}=7.85, \mathrm{p}<0.01\right)$ and none of the variance in $2^{\text {nd }}$ doping choice. Similarly, in step 3, morality failed to account for a significant proportion of both doping choices. Overall, the results showed that intentions were the most important factor for the prediction of both doping choices for athletes but perceived behavioral control and morality appeared a non-significant proportion.

With regard to the prediction of coaches' doping choices 1 and 2 (see Table 4), in step 1, intentions significantly predicted doping choice 1 , accounting for $84 \%$ of the variance $\left(F_{(1,48)}=269.58\right.$, p $\left.<0.001\right)$ and $79 \%$ of the variance in doping choice $2\left(F_{(1,48)}=183.9, \mathrm{p}<0.001\right)$. In steps 2 and 3 , perceived behavioral control and morality failed to account for a significant proportion of both doping choices. Therefore, intentions were the only variable that increased the prediction of coaches' $1^{\text {st }}$ and $2^{\text {nd }}$ doping choices.

\section{Discussion}

The purpose of this study was to analyze the doping attitudes and intentions of athletes and coaches and to investigate the application of the TPB in doping research. The results revealed that a remarkable number of athletes appeared positive about doping use. In addition, attitudes seemed to be the most important predictor of athletes' and coaches' intentions. We presume that decisions regarding doping are strongly associated with the TPB variables, especially attitudes and intention. This idea is in accordance with that put forward in several similar studies [5] [27] [28] [38]-[40], which argued that attitudes were the most important factor in the prediction of doping use, followed by perceived behavioral control and morality. Concerning the coaches' results, attitudes were the only statistically significant predictor of intentions. The other variables, subjective norms, perceived behavioral control, and morality failed to account for a significant proportion of the variance in intentions. Furthermore, the responses in doping choices, of both the athletes and the coaches, which depicted the possibility of doping use, pointed to a high correlation with intentions. In addition, intentions were the most important predictor of doping choices. Those results were the same for the athletes' as like coaches' measurements.

The analysis of the demographic characteristics showed that men were more likely than women to engage in doping choices. The significant differences in the attitudes of the male and female athletes agree with the findings of Alaranta et al. [38]. Similarly, Lucidi et al. (2004) indicated that the prevalence of men who engaged in doping choices was $5.2 \%$ compared to $1 \%$ of women. As noted in other studies [39], the higher scores of the men vs. the women point to a greater possibility of doping choices among male athletes. In addition, the results of the coaches indicated that younger coaches appeared more open to the possibility of encouraging athletes to engage in doping choices. It may be that younger coaches are more focused than older coaches on reaching major goals by whatever means.

Tavani, Colombo, Scarpino, Pacifici, and La Vecchia [41] asserted that athletes believed doping was widespread among top athletes. In our study, there were no significant differences in the athletes' attitudes according to the level of sport at which they performed. Interestingly, the scores of the coaches at the local level for all the variables were higher than those at the other levels, suggesting that they are more likely to lead their athletes toward doping use. A possible explanation is that they desire greater success and that they have major expectations of their athletes and themselves. We consider that these are important findings, and that further study is needed [42] [43] of the factors affecting the development of athletes' attitudes and intentions. In addition, we suggest that a study of athletes' attitudes in comparison to those of their coaches is needed to discover the coaches' influence.

Finally, the present study found significant differences in the attitudes of athletes who participated in individual sports as compared to those who participated in team sports. Goulet, Valois, Buist, and Cote [44] reported no relationship between attitudes to doping and the types of sports. Alaranta et colleagues [38] indicated that athletes who participated in sports that require speed and power skills were more likely to engage in doping choices. Unexpectedly, in our research, the athletes who were involved in team sports had more positive attitudes toward doping than the athletes who participated in individual sports. This finding may be explained by the co-athlete and overall team mentality. 


\section{Limitations}

The findings of this study should be considered within the context of its limitations. First of all the questionnaire was not validated in a large sample. The sample size was not very high, especially that of the coaches and there were issues of validity of some variables. In addition, a limitation is the fact that the study involved a specific national sample in Greece. In accordance with the scenario, it was far from reality for the reason to bring to the surface the inner doping attitudes and intentions of the participants. Firstly, athletes and coaches asked to imagine that they are closer to being in the Olympic Games. That is actual to elite athletes but too far from the reality of people who are doing sports in a lower level. Another limitation resulting from the scenario is that getting caught plays an important role to dope. In this study, we used the assumption that athletes will not be detected because we want to separate doping attitudes and intentions from the fear of being caught and this might influence the final answers.

\section{Conclusions}

This cross-sectional correlational survey-based study examined the psychosocial factors associated with intentions to engage in doping in a sample of Greek athletes and coaches. The results of this study showed that the most important factor for predicting doping intentions was attitude. Attitudes also influenced coaches' intentions with regard to doping choices. Coaches should have accurate knowledge about doping, drug use, and doping methods, especially adverse reactions to doping use. Previous research of the psychosocial factors affecting doping has not included the potential role played by coaches' attitudes. It would be interesting for future research to examine athletes who have engaged in doping and coaches who have suggested doping to athletes and their influence.

According to Doganis and Theodorakis [45], the physical education instructor plays an important role in shaping children's attitudes and behavior, as well as shaping the content of programs, and can influence students in a positive or negative way. In school, physical education programs should aim to shape students' beliefs about the negative health effects and unfair nature of doping use. The implementation and evaluation of such interventions in schools could be very important in the doping prevention field.

\section{References}

[1] WADA, March 2015. http://www.wada-ama.org/

[2] Doping Prevention. 2015. http://www.dopingprevention.sp.tum.de/index.php?id=2\&L=5

[3] Morente-Sánchez, J. and Zabala, M. (2013) Doping in Sport: A Review of Elite Athletes’ Attitudes, Beliefs, and Knowledge. Sports Medicine, 43, 395-411. http://dx.doi.org/10.1007/s40279-013-0037-x

[4] Ehrnborg, C. and Rosé, T. (2009) The Psychology behind Doping in Sport. Growth Hormone \& IGF Research, 19, 285-287. http://dx.doi.org/10.1016/j.ghir.2009.04.003

[5] Petróczi, A. and Aidman, E. (2009) Measuring Explicit Attitude toward Doping: Review of the Psychometric Properties of the Performance Enhancement Attitude Scale. Psychology of Sport and Exercise, 3, 390-396. http://dx.doi.org/10.1016/j.psychsport.2008.11.001

[6] Dodge, T. and Jaccard, J.J. (2008) Is Abstinence and Alternative? Predicting Adolescent Athletes' Intention to Use Performance Enhancing Substances. Journal of Health Psychology, 13, 703-711. http://dx.doi.org/10.1177/1359105307082460

[7] Laure, P., Binsinger, C. and Lecerf, T. (2003) General Practitioners and Doping in Sport: Attitudes and Experience. British Journal of Sports Medicine, 37, 335-338. http://dx.doi.org/10.1136/bjsm.37.4.335

[8] Laure, P., Lecerf, T., Friser, A. and Binsinger, C. (2004). Drugs, Recreational Drug Use and Attitudes towards Doping of High School Athletes. International Journal of Sports Medicine, 25, 133-138. http://dx.doi.org/10.1055/s-2004-819946

[9] Peretti-Watel, P., Guagliardo, V., Verger, P., Mignon, P., Pruvost, J. and Obadia, Y. (2004) Attitudes toward Doping and Recreational Drug Use among French Elite Student-Athletes. Sociology of Sport Journal, 21, 1-17.

[10] Papazisis, G., Kouvelas, D. and Mastrogianni, (2007) Anabolic Androgenic Steroid Abuse and Mood Disorder: A Case Report. International Journal of Neuropsychopharmacology, 10, 291-293. http://dx.doi.org/10.1017/S1461145706007243

[11] Schirlin, O., Rey, G., Jouvent, R., Dubal, S., Komano, O., Perez-Diaz, F. and Soussignan, R. (2009) Attentional Bias for Doping Words and Its Relation with Physical Self-Esteem in Young Adolescents. Psychology of Sport and Exercise, 


\section{6, 615-620.}

[12] Laure, P. and Binsinger, C. (2007) Doping Prevalence among Preadolescent Athletes: A 4-Year Follow-Up. British Journal of Sports Medicine, 41, 660-663. http://dx.doi.org/10.1136/bjsm.2007.035733

[13] Pope, H. and Katz, D. (2007) Psychiatric Effects of Exogenous Anabolic Androgenic Steroids. In: Wolkowitz, O.M. and Rothschild, A.J., Eds., Psychoneuroendocrinology for the Clinician, American Psychiatric Press, Washington DC.

[14] Rashid, H., Ormerod, S. and Ed, D. (2007) Anabolic Androgenic Steroids: What the Psychiatrist Needs to Know. Advances in Psychiatric Treatment, 13, 203-211. http://dx.doi.org/10.1192/apt.bp.105.000935

[15] Miller, K.E., Barnes, G.M., Sabo, D., Melnick, M.J. and Farrell, M.P. (2002) A Comparison of Health Risk Behavior in Adolescent Users of Anabolic-Androgenic Steroids, by Gender and Athlete Status. Sociology of Sport Journal, 19, 385-402.

[16] Møller, V., McNamee, M.J. and Dimeo, P., Eds. (2009) Elite Sports, Doping and Public Health. University of Southern Denmark Press, Odense.

[17] Houlihan (2002) Dying to Win. Barrie Houlihan, Barrie, 155.

[18] Verroken, M. (2000) Drug Use and Abuse in Sport. Journal of Clinical Endocrinology Metabolism, 14, 1-23. http://dx.doi.org/10.1053/beem.2000.0050

[19] Maycock, B. and Howat, P. (2005) The Barriers to Illegal Anabolic Steroid Use. Drugs Education Prevention and Policy, 12, 317-325. http://dx.doi.org/10.1080/09687630500103622

[20] Ehrnborg, C. and Rosen, T. (2009) The Psychology behind Doping in Sport. Growth Hormone \& IGF Research, 19, 285-287. http://dx.doi.org/10.1016/j.ghir.2009.04.003

[21] Corrion, K., Long, T., Smith, A. and Arripe-Longueville, F. (2009) It’s Not My Fault; It’s Not Serious. Athlete Accounts of Moral Disengagement in Competitive Sport. The Sport Psychologist, 23, 388-404.

[22] Strelan, P. and Boeckmann, R.J. (2006) Why Drug Testing in Elite Sport Does Not Work: Perceptual Deterrence Theory and the Role of Personal Moral Beliefs. Journal of Applied Social Psychology, 36, 2909-2934. http://dx.doi.org/10.1111/j.0021-9029.2006.00135.x

[23] Ajzen, I. (1988) Attitudes, Personality, and Behavior. Dorsey, Chicago.

[24] Fishbein, M. and Ajzen, I. (1975) Belief, Attitude, Intention, and Behavior: An Introduction to Theory and Research. Addison Wesley, Reading.

[25] Ajzen, I. and Fishbein, M. (2005) The Influence of Attitudes on Behavior. In: Albarracín, D., Johnson, B.T. and Zanna, M.P., Eds., The Handbook of Attitudes, Erlbaum, Mahwah, 173-221.

[26] Theodorakis, Y. (1994) Planned Behavior, Attitude Strength, Role Identity, and the Prediction of Exercise Behavior. The Sport Psychologist, 8, 149-165.

[27] Lucidi, F., Grano, C., Leone, L., Lombardo, C. and Pesce, C. (2004) Determinants of the Intention to Use Doping Substances: An Empirical Contribution in a Sample of Italian Adolescents. International Journal of Sport Psychology, 35, 133-148.

[28] Lucidi, F., Zelli, A., Mallia, L., Grano, C., Russo, P.M. and Violani, C. (2008) The Social-Cognitive Mechanisms Regulating Adolescents' Use of Doping Substances. Journal of Sports Sciences, 26, 447-456.

[29] Petróczi, A., Aidman, E. and Nepusz, T. (2008) Capturing Doping Attitudes by Self-Report Declarations and Implicit Assessment: A Methodology Study. Substance Abuse Treatment, Prevention, and Policy, 3, 9.

[30] Goulet, C., Valois, P., Buist, A. and Cote, M. (2010) Predictors of the Use of Performance-Enhancing Substances by Young Athletes. Clinical Journal of Sport Medicine, 20, 243-248. http://dx.doi.org/10.1097/JSM.0b013e3181e0b935

[31] Zelli, A., Mallia, L. and Lucidi, F. (2010) The Contribution of Interpersonal Appraisals to a Social-Cognitive Analysis of Adolescents' Doping Use. Psychology of Sport and Exercise, 11, 304-311. http://dx.doi.org/10.1016/j.psychsport.2010.02.008

[32] Petróczi, A., Mazanov, J., Nepusz, T., Backhouse, S. and Naughton, D.P. (2008) Comfort in Big Numbers: Does OverEstimation of Doping Prevalence in Others Indicate Self-Involvement? Journal of Occupational Medicine and Toxicology, 3, 19.

[33] Weiss, M.R., Smith, A.L. and Stuntz, C.P. (2008) Moral Development in Sport and Physical Activity. In: Shorn, T., Ed., Advances in Sport Psychology, 3rd Edition, Human Kinetics, Champaign, 187-210.

[34] Morente-Sanchez, J. and Zabala, M. (2013) Doping in Sport: A Review of Elite Athletes' Attitudes, Beliefs, and Knowledge. Sports Medicine, 43, 395-411. http://dx.doi.org/10.1007/s40279-013-0037-x

[35] Kaiser, G.F. (2006) A Moral Extension of the Theory of Planned Behavior: Norms and Anticipated Feelings of Regret in Conservationism. Personality and Individual Differences, 41, 71-81. http://dx.doi.org/10.1016/j.paid.2005.11.028 
[36] Ajzen, I. (2002) Constructing a TpB Questionnaire: Conceptual and Methodological Considerations. http://www-nix.oit.umass.edu/ aizen/tpb.html

[37] Ajzen, I., Brown, T.C. and Carvajal, F. (2004) Explaining the Discrepancy between Intentions and Actions: The Case of Hypothetical Bias in Contingent Valuation. Personality and Social Psychology Bulletin, 30, 1108-1121. http://dx.doi.org/10.1177/0146167204264079

[38] Alaranta, A., Alaranta, H., Holmila, J., Palmu, P., Pietilä, K. and Helenius, I. (2006) Self-Reported Attitudes of Elite Athletes towards Doping: Differences between Types of Sport. International Journal of Sports Medicine, 27, 842-846. http://dx.doi.org/10.1055/s-2005-872969

[39] Petróczi, A. (2007) Attitudes and Doping: A Structural Equation Analysis of the Relationship between Athletes' Attitudes, Sport Orientation and Doping Behaviour. Substance Abuse Treatment, Prevention, and Policy, 9, 34. http://dx.doi.org/10.1186/1747-597X-2-34

[40] Wiefferink, C.H., Detma, S.B., Couman, B., Vogel, T. and Paulussen, T.G.W. (2007) Social Psychological Determinants of the Use of Performance-Enhancing Drugs by Gym Users. Health Education Research Advance, 23, 70-80. http://dx.doi.org/10.1093/her/cym004

[41] Tavani, A., Colombo, P., Scarpino, P.Z., Pacifici, R. and La Vecchia, C. (2013) Beliefs on and Attitude toward Doping Use among Athletes: An Italian Survey. Italian Journal of Public Health, 9, 8669.

[42] Backhouse, S., McKenna, J. and Atkin, A. (2009) Reviewing Research into Attitudes towards Doping in Sport: Time to Take Stock. Journal of Science and Medicine in Sport, 12, S80-S81. http://dx.doi.org/10.1016/j.jsams.2008.12.195

[43] Backhouse, S., McKenna, J., Robinson, S. and Atkin, A. (2007) WADA International Literature Review: Attitudes, Behaviours, Knowledge and Education-Drugs in Sport: Past, Present and Future. Leeds Metropolitan University Carnegie Research Institute, Prepared for World Anti-Doping Agency.

[44] Goulet, C., Valois, P., Buist, A. and Cote, M. (2010) Predictors of the Use of Performance-Enhancing Substances by Young Athletes. Clinical Journal of Sport Medicine, 20, 243-248.

[45] Doganis, G. and Theodorakis, Y. (1995) The Influence of Attitude on Exercise Participation. In: Biddle, S.J.H., Ed., European Perspectives on Exercise and Sport Psychology, Human Kinetics Publishers, Champaign, 26-49. 